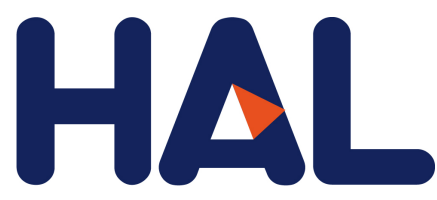

archives-ouvertes

\title{
Smooth plasma etching of GeSn nanowires for gate-all-around field effect transistors
}

E Eustache, M Mahjoub, Y Guerfi, S Labau, J Aubin, J Hartmann, F Bassani, S David, B Salem

\section{To cite this version:}

E Eustache, M Mahjoub, Y Guerfi, S Labau, J Aubin, et al.. Smooth plasma etching of GeSn nanowires for gate-all-around field effect transistors. Semiconductor Science and Technology, IOP Publishing, 2021, 36 (6), pp.065018. 10.1088/1361-6641/abfbb5 . hal-03375044

\section{HAL Id: hal-03375044 \\ https://hal.archives-ouvertes.fr/hal-03375044}

Submitted on 18 Oct 2021

HAL is a multi-disciplinary open access archive for the deposit and dissemination of scientific research documents, whether they are published or not. The documents may come from teaching and research institutions in France or abroad, or from public or private research centers.
L'archive ouverte pluridisciplinaire HAL, est destinée au dépôt et à la diffusion de documents scientifiques de niveau recherche, publiés ou non, émanant des établissements d'enseignement et de recherche français ou étrangers, des laboratoires publics ou privés. 


\title{
Smooth plasma etching of GeSn nanowires for gate-all-around field effect transistors
}

\author{
E Eustache ${ }^{1}$, M A Mahjoub ${ }^{1}$, Y Guerfi $^{1}$, S Labau ${ }^{1}$, J Aubin ${ }^{2}$, J M Hartmann ${ }^{2}(1)$ \\ F Bassani ${ }^{1}$ (D) S David ${ }^{1}$ and B Salem ${ }^{1, *}$ (D) \\ ${ }^{1}$ University Grenoble Alpes, CNRS, CEA-LETI, Grenoble INP, LTM, F-38054 Grenoble, France \\ ${ }^{2}$ University Grenoble Alpes, CEA-LETI, F-38054 Grenoble, France \\ E-mail: bassem.salem@cea.fr
}

Received 2 February 2021, revised 6 April 2021

Accepted for publication 26 April 2021

Published $\mathrm{xx}$ xx xxxx

\begin{abstract}
We report on the nanopatterning of horizontal and vertical germanium-tin $\left(\mathrm{Ge}_{1-x} \mathrm{Sn}_{x}\right.$ or GeSn) nanowires by inductively coupled plasma reactive ion etching for gate-all-around field effect transistors. First, a chlorine based chemistry has been investigated and optimal conditions identified for GeSn $6 \%$ alloys. Then, plasma etching was optimized to etch high Sn content GeSn alloys (up to 15\%) with a high anisotropy, smooth sidewalls and a high selectivity versus a hydrogen silsesquioxane hard mask. We have shown that, in order to obtain smooth surfaces after plasma etching, a $\mathrm{HCl}$ pre-treatment was mandatory to eliminate the native $\mathrm{Sn}$ and $\mathrm{Ge}$ oxides. This behavior was even more pronounced for high Sn contents. Finally, we succeeded in patterning $20 \mathrm{~nm}$ wide suspended beams from GeSn layers with $\mathrm{Sn}$ concentrations up to $15 \%$ Sn.
\end{abstract}

Keywords: germanium-tin nanowire, GAA-FET, plasma etching, XPS

(Some figures may appear in color only in the online journal)

\section{Introduction}

Germanium tin alloys $\left(\mathrm{Ge}_{1-x} \mathrm{Sn}_{x}\right)$ are promising candidates for next-generation complementary metal oxide semiconductor (CMOS) circuits, low power consumption devices and Si-photonics [1]. The energy bandgap of the GeSn alloys can indeed be controlled by changing the $\mathrm{Sn}$ content [2, 3]. For $\mathrm{Sn}$ contents $8 \%$ and above, unstrained GeSn exhibits a low and direct band gap, with an increase of carrier mobility and electron injection velocity compared to pure Ge [4]. For those reasons, GeSn alloys are currently being investigated as channel materials in next generation devices. Indeed, combining direct band-to-band tunneling and low bandgap should yield efficient tunnel field effect transistors [5]. Moreover, as a group IV alloy, GeSn is an ideal semiconductor for the co-integration of high speed CMOS transistors and Si photonic devices in the

* Author to whom any correspondence should be addressed. short-wave infrared range [6-8]. Gate-all-around field effect transistors (GAA-FETs) are considered as being the 'ultimate' devices to continue the downscaling of transistors. Such an architecture yields the best electrostatic control over the channel by the gate, limiting short-channel effects and significantly reducing the off-state leakage current $\left(I_{\mathrm{OFF}}\right)$. Vertical nanowires [9] and stacked nano-sheets [10], which have low footprints, are attractive candidates to integrate GAA-FETs in electronic circuits. GeSn nanowires patterning by inductively coupled plasma reactive ion etching (ICP-RIE) will then be key. Indeed, it will define the channel, one of the most crucial parts of such transistors.

Because of the low Sn solubility in Ge (less than $1 \%$ at thermal equilibrium), it is difficult to grow (and process) high $\mathrm{Sn}$ content GeSn layers. The Sn concentration should be high enough to have the desirable electrical properties, but not too high, to minimize process complexity. The thermal processing window is indeed substantially reduced as the $\mathrm{Sn}$ concentration increases (Sn surface segregation/precipitation) [11]. The 
fabrication of gate stacks [12] or ohmic contacts [13, 14] on GeSn was investigated. However, data are scarce concerning the plasma etching of GeSn. As the current study will show, different etching behaviors happen when the Sn content changes. Gupta et al [15] found $\mathrm{Sn}-\mathrm{F}$ bonds on the GeSn surface after $\mathrm{CF}_{4}$ plasma exposition. This study suggested that a $\mathrm{SnF}_{x}$ passivation layer was formed, preventing $\mathrm{CF}_{4}$ plasma etching. After exposure to ambient air, there was $\mathrm{SnO}_{y} \mathrm{~F}_{x}$ on a GeSn surface exposed to a $\mathrm{CF}_{4}$ plasma which can be removed thanks to a dip in diluted $\mathrm{HCl}$. Shang et al [16] used this behavior for their digital dry-wet etching of GeSn. By alternating $\mathrm{CF}_{4}$ plasma etchings and dips in $\mathrm{HCl}$, they were indeed able to etch 1.5-3.2 $\mathrm{nm}$ of GeSn per cycle. This type of process is very effective to precisely define a pattern (fin or nanowire). It is however unsuitable for the anisotropic etching of patterns from as-grown $\mathrm{GeSn}$ films. Although a $\mathrm{Cl}_{2}$ chemistry was mentioned [17], plasma etching processes were not reported in recent studies on nanoscale patterned GeSn transistors [5, 17]. Milord et al [9] used a fast etching process $\left(340 \mathrm{~nm} \mathrm{~min}^{-1}\right)$ to fabricate micrometer scale disks. They were able to vertically etch hundreds of nm thick GeSn layers thanks to the addition of $\mathrm{O}_{2}$ in a $\mathrm{Cl}_{2} / \mathrm{N}_{2}$ mixture. $\mathrm{O}_{2}$ may have allowed the formation of weakly volatile species, which passivated the sidewalls, while ions brought enough energy to assist desorption or remove these species horizontally by physical sputtering [18]. However, $10 \mathrm{~nm}$ range patterns would require a slower and more precise process.

This article focuses on nanopatterning by ICP-RIE of GeSn alloys with $\mathrm{Sn}$ contents in the 6\%-15\% range. The morphology of nanowires and the chemical composition of the surface have been analyzed by scanning electron microscopy and x-ray photoelectron spectroscopy. We show that, in order to obtain smooth surfaces after plasma etching, $\mathrm{HCl}$ pretreatment is mandatory to eliminate the native $\mathrm{Sn}$ and $\mathrm{Ge}$ oxides.

\section{Experimental details}

The GeSn samples used in this study were grown in the $300{ }^{\circ} \mathrm{C}-350{ }^{\circ} \mathrm{C}$ range on Ge strain-relaxed buffers, themselves on $200 \mathrm{~mm} \mathrm{Si} \mathrm{(100)} \mathrm{substrates,} \mathrm{by} \mathrm{reduced} \mathrm{pressure} \mathrm{chem-}$ ical vapor deposition. The $50 \mathrm{~nm}$ thick GeSn 6\%, 10\% and $15 \%$ layers were fully strained, as confirmed by x-ray diffraction [19]. Etching masks were defined by e-beam lithography (JOEL6300FS system) using a $60 \mathrm{~nm}$ thick hydrogen silsesquioxane (HSQ) resist. Two types of patterns were studied: dots with a diameter ranging from 10 to $110 \mathrm{~nm}$ for vertical GAA-FETs and fins with line widths ranging from 10 to $100 \mathrm{~nm}$ and a pitch of $50-100 \mathrm{~nm}$ for horizontal suspended GAA-FETs (after further removal of the under layer). The $1 \mathrm{~cm}^{2}$ samples were bonded on 4 inches silicon wafers using poly methyl methacrylate and loaded in an Oxford Plasma Lab 100 ICP-RIE plasma etching chamber for fins and dots patterning. Samples were characterized by scanning electron microscopy (SEM) in tilted view at $85^{\circ}$ from the surface using a ZEISS ULTRA $^{+}$microscope in order to evaluate the fins profile and etching rates.

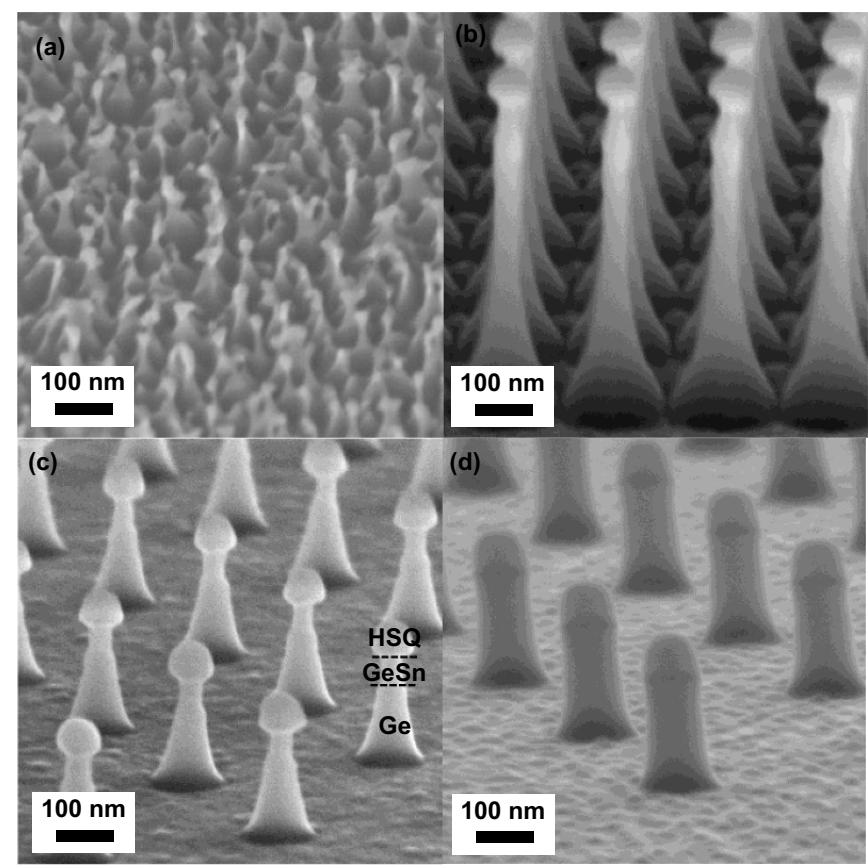

Figure 1. $85^{\circ}$ tilted SEM images of $\mathrm{Ge}_{0.94} \mathrm{Sn}_{0.06} / \mathrm{Ge}$ after $60 \mathrm{~s}$ plasma etching with (a) $25 / 10 / 25$, (b) $100 / 10 / 25$, (c) $50 / 10 / 25$, and (d) $18 / 5 / 13 \mathrm{sccm}$ of $\mathrm{Cl}_{2} / \mathrm{O}_{2} / \mathrm{N}_{2}$.

XPS analysis of the GeSn surface was carried out immediately after etching (a few minutes in ambient air only) in a customized thermo electron theta 300 spectrometer, using a high resolution monochromatic $\mathrm{Al} \mathrm{K} \alpha$ source at $1486.6 \mathrm{eV}$. The detection angle was fixed at $21^{\circ}$ to the normal of the wafer. XPS spectra were calibrated according to the $\mathrm{C} 1 \mathrm{~s}$ binding energy of $285 \mathrm{eV}$. Pass energy for narrow scan windows was set as $23.5 \mathrm{eV}$ with a scan step size of $0.2 \mathrm{eV}$. The data were fitted using a Shirley function for the background and a pseudoVoigt function with a Lorentzian contribution of $30 \%$ for the peaks. All parameters were left free during fitting, except for the full widths at half maximum that were kept the same for the different contributions of one element.

\section{Results and discussion}

\subsection{Patterning of $\mathrm{Ge}_{0.94} \mathrm{Sn}_{0.06}$}

We studied the etching process of GeSn $6 \% \mathrm{Sn}$ with a $\mathrm{Cl}_{2} / \mathrm{O}_{2} / \mathrm{N}_{2}$ chemistry. To obtain a precise control and low etching rates, ICP and platen radio-frequency powers were limited to $100 \mathrm{~W}$. Figure 1 shows the influence of the $\mathrm{Cl}_{2} / \mathrm{O}_{2} / \mathrm{N}_{2}$ gas flows. Varying these parameters is a straightforward method to adjust the ratio between etching and passivation. The resulting etching rate and verticality are severely impacted by chemistry changes. The starting $\mathrm{Cl}_{2} / \mathrm{O}_{2} / \mathrm{N}_{2}$ gas mixture was fixed at $25 / 10 / 25 \mathrm{sccm}$. It resulted in the formation of so-called 'grass', as shown figure 1(a). This behavior usually occurs when an etch product is re-deposited, or, more probably in our case, when passivation is too strong against etching, generating needles all over the etched surface. Increasing the chlorine flow to $100 \mathrm{sccm}$ results in a faster etching rate of $\approx 10 \mathrm{~nm} \mathrm{~s}^{-1}$, 


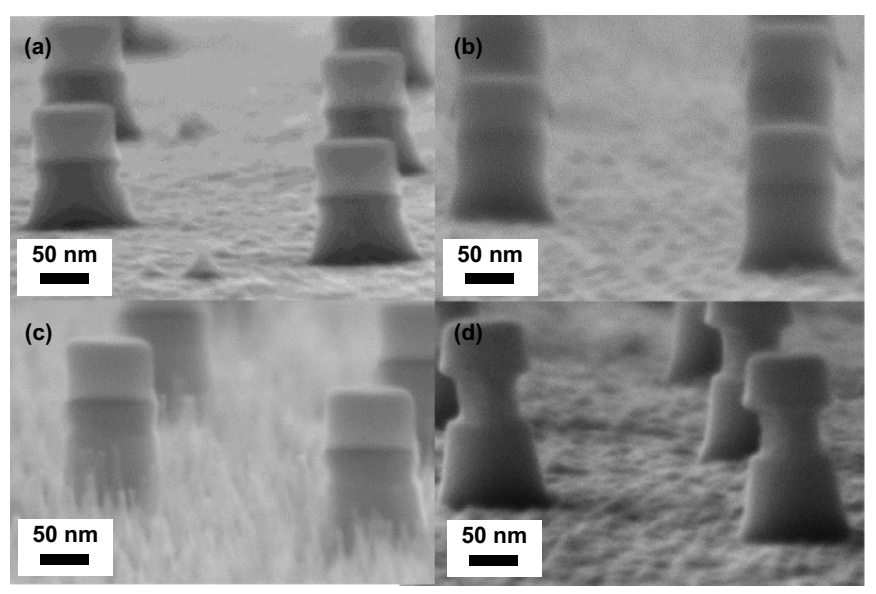

Figure 2. $85^{\circ}$ tilted SEM images of etched samples: $\mathrm{Ge}_{0.9} \mathrm{Sn}_{0.1} / \mathrm{Ge}$ at (a) $10 \mathrm{mTorr}$ and (b) $5 \mathrm{mTorr} ; \mathrm{Ge}_{085} \mathrm{Sn}_{0.15} / \mathrm{Ge}$ at (c) $5 \mathrm{mTorr}$ and (d) 5 mTorr without $\mathrm{O}_{2}$.

which is not desirable for the fabrication of nanoscale GeSn fins and dots (figure 1(b)). Reducing the chlorine flow to a moderate value of $50 \mathrm{sccm}$ reduced the etching rate to $3 \mathrm{~nm} \mathrm{~s}^{-1}$ and yielded smooth sidewalls. There was however an overetching of GeSn below the HSQ patterns (i.e. an undercut), while dots were conically shaped (figure 1(c)). This was likely due to a poor surface passivation of the GeSn sidewalls.

Figure 1(d) shows the best result obtained with optimized parameters: the ICP power was reduced to $50 \mathrm{~W}$ to decrease the plasma density and the platen power was kept to $50 \mathrm{~W}$. The overall gas flow was reduced and the $\mathrm{O}_{2}$ and $\mathrm{N}_{2}$ flows increased, proportionally, to improve sidewall passivation: $\mathrm{Cl}_{2} / \mathrm{O}_{2} / \mathrm{N}_{2}$ flows of $18 / 5 / 13 \mathrm{sccm}$ were then used, with a 10 mTorr etch pressure. The over-etching of GeSn below the HSQ patterns was then totally suppressed. With such process, sidewalls were vertical and smooth while the etching rate was limited to $\approx 3.4 \mathrm{~nm} \mathrm{~s}^{-1}$.

\subsection{Transfer of the process to $G e_{0.9} S n_{0.1}$ and $G e_{0.85} S n_{0.15}$}

The optimized etching recipes were used on GeSn layers with higher Sn contents $(10 \%$ and $15 \%)$. The etch rate decreased to $\approx 1.5 \mathrm{~nm} \mathrm{~s}^{-1}$ for $10 \%$ of $\mathrm{Sn}$, with a reduced notching in the GeSn layer, as seen in figure 2(a). Decreasing the etch pressure from 10 mTorr down to 5 mTorr (figure 2(b)) restored the verticality of the sidewalls.

For $15 \%$ of Sn, the notch was still present even at 5 mTorr in figure 2(c). There was also unwanted needles on the bottom surface. A decrease of the pressure to $3 \mathrm{mTorr}$, which is the lowest pressure achievable within our equipment with these gases flows and pumping unit, restored the verticality of the sidewalls, but needles remained (not shown here). As needles in an etching process with passivation gas usually originate from too much passivation, we tried to remove oxygen from the recipe. As shown in figure 2(d), needles indeed disappeared, but the verticality of the patterns was lost, with a large etching of the GeSn layer under the HSQ mask.

\subsection{XPS study of the etching process}

To determine the origin of the needles, XPS analyses were carried out.

The top row of figure 3 shows the fitted Ge3d and Sn4d XPS spectra of the $\mathrm{Ge}_{0.94} \mathrm{Sn}_{0.06}$ surface (figure 3 S6-ref) and the same surface after $15 \mathrm{~s}$ (figure 3 S6-15) and $60 \mathrm{~s}$ (figure 3 S6-60) of etching. The bottom row shows XPS spectra of the $\mathrm{Ge}_{0.85} \mathrm{Sn}_{0.15}$ surface (figure $3 \mathrm{~S} 15 \mathrm{ref}$ ) and the same surface after 15 s (figure 3 S15-15) and 60 s (figure 3 S15-60) of etching. Regardless the sample, XPS spectra show a doublet at 22.4 and $24.4 \mathrm{eV}$, attributed to the $\mathrm{Ge} \mathrm{Ge} 3 \mathrm{~d}_{5 / 2}$ and $\mathrm{Ge} 3 \mathrm{~d}_{3 / 2}$ and a board peak at $31.88 \mathrm{eV}$ attributed to $\mathrm{Ge}$ oxide $(\mathrm{Ge}-\mathrm{O})$.

For S6ref and S15ref, the XPS spectra shows the presence of an additional doublet at 24.4 and 23.7 and a broad peak at $25.65 \mathrm{eV}$ attributed to the $\mathrm{Sn} 4 \mathrm{~d}_{5 / 2}$ and $\mathrm{Sn} 4 \mathrm{~d}_{3 / 2}$ doublet and to $\mathrm{Sn}$ oxide $(\mathrm{Sn}-\mathrm{O})$, respectively. The intensity of the $\mathrm{Sn}-\mathrm{O}$ peak is higher in the S15ref case, probably due to the higher $\mathrm{Sn}$ concentration. After $15 \mathrm{~s}$ of etch, the $\mathrm{Sn}-\mathrm{O}$ peak is completely removed for S6-15 and S15-15. Moreover, the XPS spectra show an important decrease of the $\mathrm{Ge}-\mathrm{O}$ peak in the S6ref case. This is not the case for the S15-15, with an almost steady $\mathrm{Ge}-\mathrm{O}$ peak. This can be explained by a segregation of $\mathrm{Sn}-\mathrm{O}$ compounds at the surface of GeSn, resulting in some micro-masking and therefore high surface roughness and/or the presence of needles, since the $\mathrm{Sn}-\mathrm{O}$ etching seems to be faster.

After $60 \mathrm{~s}$ of etch, the GeSn layer was completely etched for S6-60 and S15-60 surfaces.

To confirm these hypotheses, the atomic percentages $(\%)$ of the different chemical compound detected on the GeSn surface were calculated with the Thermo Avantage ${ }^{\circledR}$ software. Table 1 gives the atomic percentages of Ge and Sn compounds. For a better understanding, three additional parameters were defined:

$$
\begin{gathered}
\mathrm{St}_{\mathrm{Sn}}(\%)=\frac{\mathrm{Sn} \%}{\mathrm{Sn} \%+\mathrm{Ge} \%} \times 100 \\
\mathrm{P}_{\mathrm{Ge}-\mathrm{O}(\%)}=\frac{\mathrm{Ge}-\mathrm{O} \%}{\mathrm{Ge}-\mathrm{Ge} \%+\mathrm{Ge}-\mathrm{O} \%} \times 100 \\
\mathrm{P}_{\mathrm{Sn}-\mathrm{O}(\%)}=\frac{\mathrm{Sn}-\mathrm{O} \%}{\mathrm{Sn}-\mathrm{Sn} \%+\mathrm{Sn}-\mathrm{O} \%} \times 100
\end{gathered}
$$

where $\mathrm{St}_{\mathrm{Sn}}(\%)$ is the $\mathrm{Sn}$ percentage in the GeSn alloy, $\mathrm{P}_{\mathrm{Ge}-\mathrm{O}}$ represents the $\mathrm{Ge}-\mathrm{O}(\%)$ in the total $\mathrm{Ge}$ compound and $\mathrm{P}_{\mathrm{Sn}-\mathrm{O}}$ represent the $\mathrm{Sn}-\mathrm{O}(\%)$ in the total $\mathrm{Sn}$ compound.

$\mathrm{Sn}$ concentrations close to the surface were higher than bulk values in $\mathrm{Ge}_{0.94} \mathrm{Sn}_{0.06}$ (S6ref) and $\mathrm{Ge}_{0.85} \mathrm{Sn}_{0.15}$ (S15ref) samples. They were indeed equal to $9.5 \%$ and $22.5 \%$ instead of $6 \%$ and $15 \%$ for $\mathrm{Ge}_{0.94} \mathrm{Sn}_{0.06}$ and $\mathrm{Ge}_{0.85} \mathrm{Sn}_{0.15}$, respectively. There was thus some $\mathrm{Sn}$ surface segregation, all the more so for high Sn content layers.

After $15 \mathrm{~s}$ of etching, the $\mathrm{P}_{\mathrm{Sn}-\mathrm{O}}(\%)$ was 0 for $\mathrm{Ge}_{0.94} \mathrm{Sn}_{0.06}$ and $\mathrm{Ge}_{0.85} \mathrm{Sn}_{0.15}$ surfaces, showing that $\mathrm{Sn}-\mathrm{O}$ was completely removed. Meanwhile, $\mathrm{P}_{\mathrm{Ge}-\mathrm{O}}(\%)$ decreased, after $15 \mathrm{~s}$ of etching, from $31.9 \%$ down to $17.3 \%$ for $\mathrm{Ge}_{0.94} \mathrm{Sn}_{0.06}$, at variance 

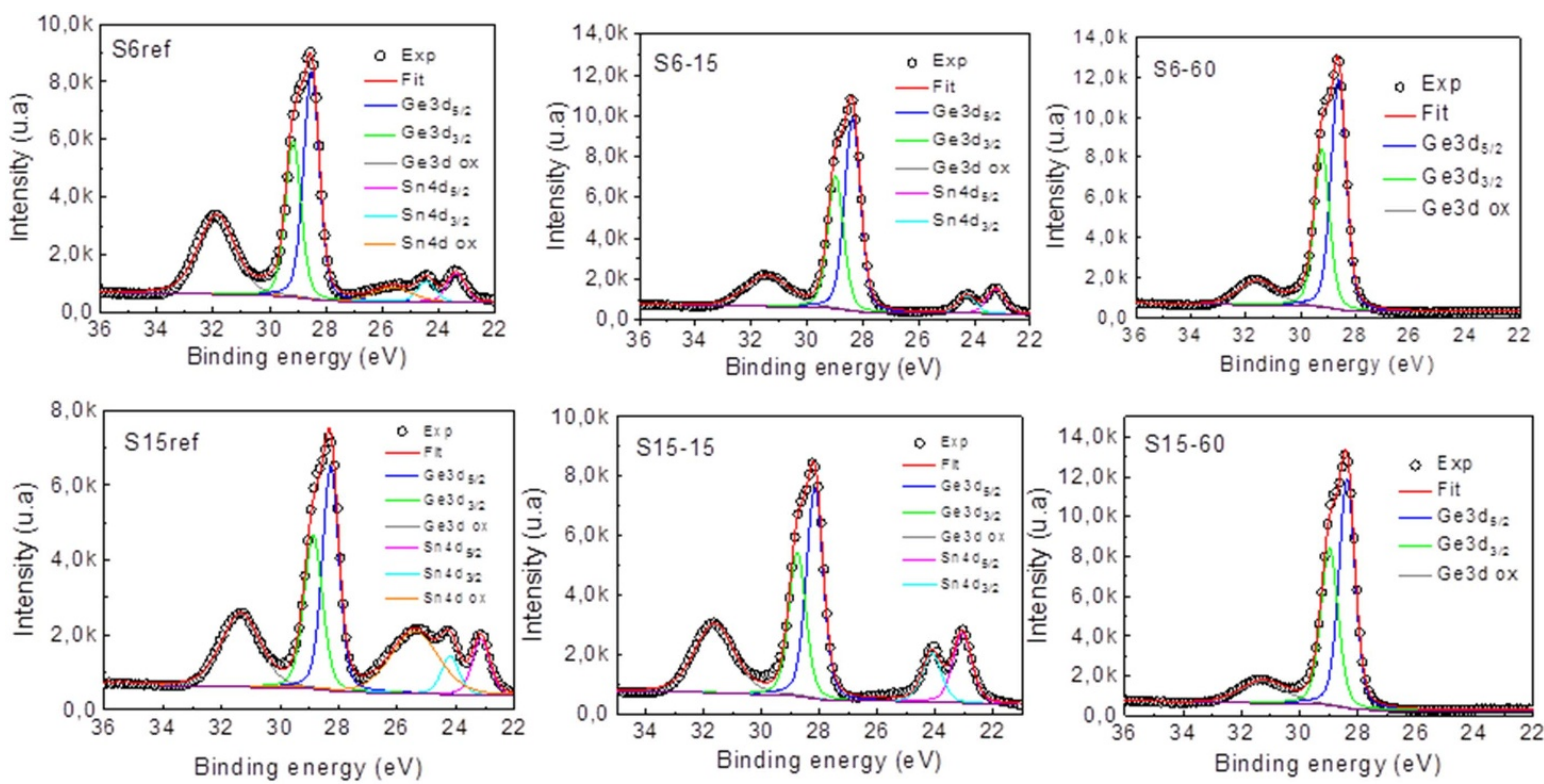

Figure 3. XPS spectra of Ge3d and Sn4d for (top row) the $\mathrm{Ge}_{0.94} \mathrm{Sn}_{0.06}$ reference sample and the same sample after 15 and $60 \mathrm{~s}$ of etching and (bottom row) the $\mathrm{Ge}_{0.85} \mathrm{Sn}_{0.15}$ reference sample and the same sample after 15 and $60 \mathrm{~s}$ of etching.

Table 1. Chemical composition of $\mathrm{Ge}_{0.96} \mathrm{Sn}_{0.06}$ and $\mathrm{Ge}_{0.85} \mathrm{Sn}_{0.15}$ surfaces before and after $15 \mathrm{~s}$ of etching.

\begin{tabular}{lccccccc}
\hline & $\mathrm{Ge}-\mathrm{Ge}(\%)$ & $\mathrm{Ge}-\mathrm{O}(\%)$ & $\mathrm{Sn}-\mathrm{Sn}(\%)$ & $\mathrm{Sn}-\mathrm{O}(\%)$ & $\mathrm{P}_{\mathrm{Ge}-\mathrm{O}}(\%)$ & $\mathrm{P}_{\mathrm{Sn}-\mathrm{O}}(\%)$ & $\mathrm{St}_{\mathrm{Sn}}(\%)$ \\
\hline S6ref & 31.8 & 14.9 & 3.6 & 0.8 & 31.9 & 17.9 & 9.5 \\
S6ref@ 15 s & 49.7 & 10.4 & 4.5 & 0 & 17.3 & 0 & 6.5 \\
etch & & & & & 30.1 & 39 & 22.5 \\
S15ref & 29.9 & 12.9 & 5.9 & 0 & 29.9 & 0 & 19.4 \\
S15ref@ 15 s & 29.9 & 12.8 & 8.4 & & & & \\
etch & & & & &
\end{tabular}

with $\mathrm{Ge}_{0.85} \mathrm{Sn}_{0.15}$, with a $\mathrm{P}_{\mathrm{Ge}-\mathrm{O}}(\%)$ staying more or less constant at $30 \%$ (table 1). All of this confirms that Sn-O etching was faster and the micro-masking hypothesis. Indeed, the $\mathrm{Sn}-\mathrm{O}$ percentage was lower in the $\mathrm{Ge}_{0.94} \mathrm{Sn}_{0.06}$ case, resulting in its complete removal before the $15 \mathrm{~s}$ of etching, some removal of $\mathrm{Ge}-\mathrm{O}$ and a $\mathrm{Sn}$ surface concentration closer to its bulk value, then $(6.5 \%$ instead of $6 \%)$. This was not the case for $\mathrm{Ge}_{0.85} \mathrm{Sn}_{0.15}$, as the starting percentage of $\mathrm{Sn}-\mathrm{O}$ was much higher. The $\mathrm{Ge}-\mathrm{O}$ percentage stayed constant, then, while the Sn surface concentration remained definitely higher than in bulk value (19.4\% instead of $15 \%)$.

XPS has thus shown that oxidized Sn on the GeSn surface was the origin of the micro-masking of GeSn, notably for high Sn contents. For that, samples were thus dipped in a $10 \% \mathrm{HCl}$ solution prior to plasma etching, in order to remove the Ge and Sn surface oxide. Figure 4 shows a $15 \%$ Sn sample etched with the optimized process at $5 \mathrm{mTorr}$. Thanks to this process, needles have disappeared, sidewalls are perfectly smooth and the GeSn notch was removed.

\subsection{GeSn horizontal nanowire formation for GAA MOSFET}

In this last section, a process sequence for the fabrication of horizontal suspended $\mathrm{Ge}_{0.9} \mathrm{Sn}_{0.1}$ nanowires for next generation GAA-FETs based on sequential GeSn and Ge plasma etching

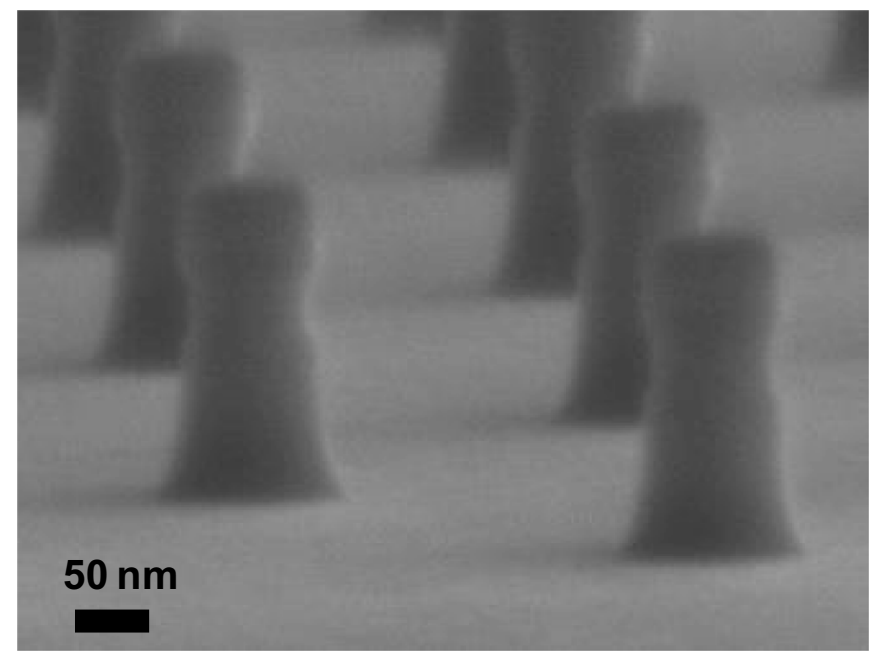

Figure 4. $85^{\circ}$ tilted SEM image of a $\mathrm{Ge}_{085} \mathrm{Sn}_{0.15}$ sample after a dip in $\mathrm{HCl}$ prior to ICP-RIE.

is presented. The first step consists in the definition of the HSQ hard mask by electron beam lithography. Nanowires with diameters ranging from 5 to $100 \mathrm{~nm}$ were targeted. We focus here on single fins $25 \mathrm{~nm}$ wide (figure 5(a)) and on networks of 5 fins $20 \mathrm{~nm}$ wide (figure 5(b)). GeSn/Ge fins were then 

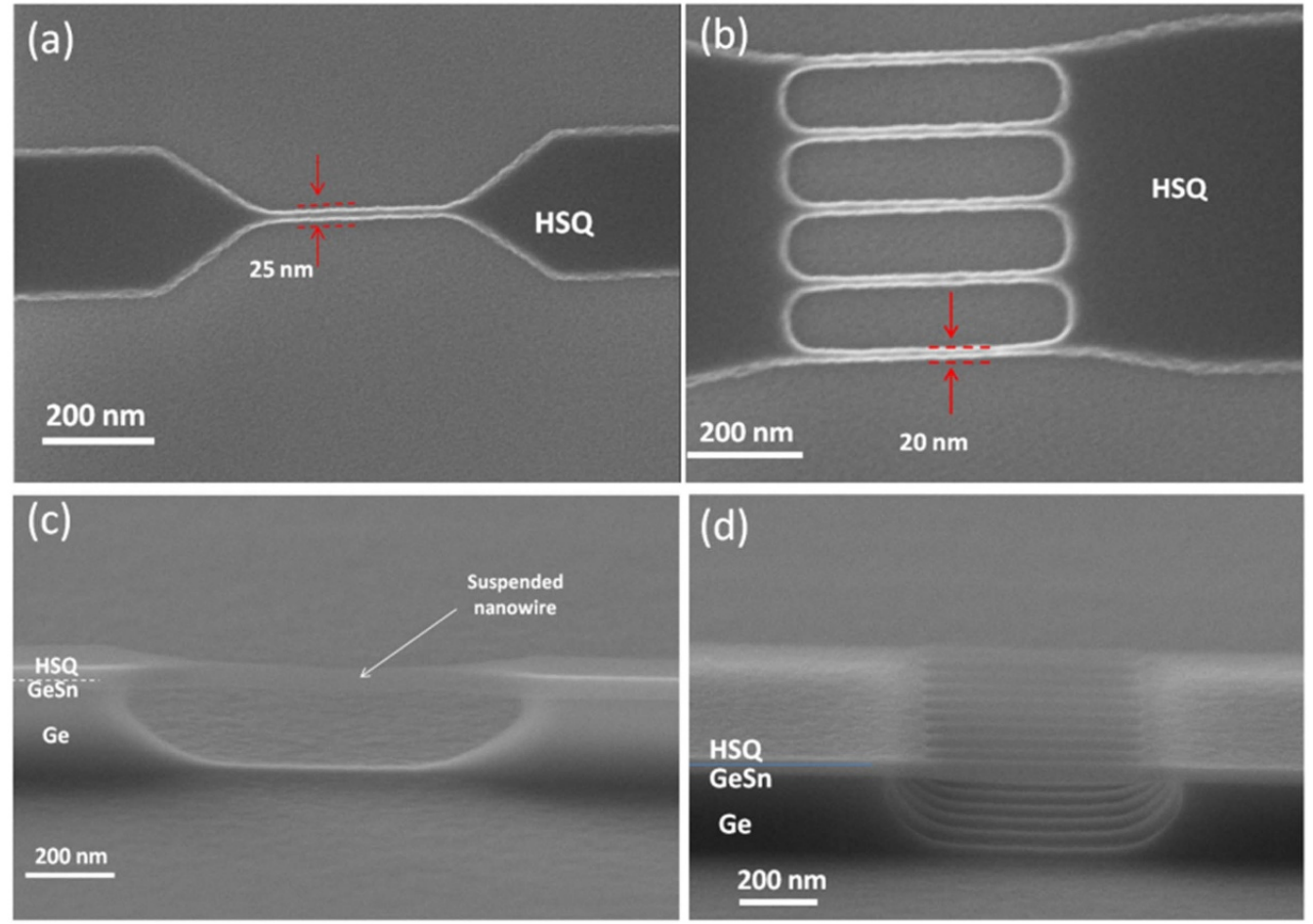

Figure 5. Process technology for the fabrication of suspended GeSn nanowires: (a) and (b) single and network of HSQ hard mask fins obtained by electron beam lithography. (c) and (d) Single and network of suspended GeSn nanowires with HSQ resist still present.

patterned by anisotropic plasma etching using the developed recipe (not shown). After that, Ge was selectively removed thanks to $\mathrm{CF}_{4}$ isotropic ICP plasma etching, liberating the $\mathrm{Ge}_{0.9} \mathrm{Sn}_{0.1}$ nanowires. Figures 5(c) and (d) show a single and a network of $10 \mathrm{GeSn}$ suspended nanowires. Thanks to the oxygen passivation during etching with our optimized recipe, the GeSn nanowires were perfectly protected during the Ge underetching step. Finally, the residual HSQ resist was etched in hydrofluoric acid, the sample surface rinsed in deionized water and dried with a $\mathrm{N}_{2}$ flow. Suspended GeSn nanowires with such small diameters are highly desirable in ultimate GAAFETs.

\section{Conclusion}

A process flow for the fabrication of GeSn nanowires for next generation GAA-FETs was evaluated. An anisotropic plasma etching that used a $\mathrm{Cl}_{2} / \mathrm{O}_{2} / \mathrm{N}_{2}$ gas mixture was optimized in an ICP-RIE etching equipment. Gas flow, pressure and ICP power were adjusted to have a smooth and anisotropic etching of a GeSn $6 \%$ layer. The optimized etching process was then performed on GeSn layers with higher Sn concentrations. Etching parameters were adapted to avoid the presence of a notch in the GeSn layer (on top of Ge). Thanks to a pressure decrease and a better passivation capability, we were able to anisotropically etch GeSn alloys with up to $15 \%$ of $\mathrm{Sn}$, with no notch anymore, smooth sidewalls and a high selectivity with respect to the HSQ hard mask. Finally, a process flow for the fabrication of horizontal suspended nanowires was successfully developed. The later could be used for the realization of next generation GeSn GAA-FETs.

\section{Data availability statement}

All data that support the findings of this study are included within the article (and any supplementary files).

\section{Acknowledgments}

This work was partly supported by the French RENATECH network through the PTA technological platforms in Grenoble and by the EquipEx IMPACT program, managed by the ANR French agency (ANR-10-EQPX-33).

\section{ORCID iDs}

J M Hartmann (D) https://orcid.org/0000-0001-7006-8586

F Bassani (D) https://orcid.org/0000-0001-8688-1328

B Salem (D) https://orcid.org/0000-0001-8038-3205

\section{References}

[1] Soref R 2015 Enabling $2 \mu \mathrm{m}$ communications Nat. Photon. $9358-9$

[2] Jenkins D W and Dow J D 1987 Electronic properties of metastable $\mathrm{Ge}_{\mathrm{x}} \mathrm{Sn}_{1-\mathrm{x}}$ alloys Phys. Rev. B 36 7994-8000

[3] Ghetmiri S A et al 2014 Direct-bandgap GeSn grown on silicon with $2230 \mathrm{~nm}$ photoluminescence Appl. Phys. Lett. 105151109

[4] Wirths S, Buca D and Mantl S 2016 Si-Ge-Sn alloys: from growth to applications Prog. Cryst. Growth Charact. Mater. 62 1-39 
[5] Schulze J et al 2015 Vertical Ge and GeSn heterojunction gate-all-around tunneling field effect transistors Solid-State Electron. 110 59-64

[6] Zhang Q, Liu Y, Yan J, Zhang C, Hao Y and Han G 2015 Theoretical investigation of tensile strained GeSn waveguide with $\mathrm{Si}_{3} \mathrm{~N}_{4}$ liner stressor for mid-infrared detector and modulator applications Opt. Express 237924

[7] Su S et al $2011 \mathrm{GeSn}$ p-i-n photodetector for all telecommunication bands detection Opt. Express 196400

[8] Wang W et al 2018 High-performance GeSn photodetector and fin field-effect transistor (FinFET) on an advanced GeSn-on-insulator platform Opt. Express 2610305

[9] Guerfi Y and Larrieu G 2016 Vertical silicon nanowire field effect transistors with nanoscale gate-all-around Nanoscale Res. Lett. 11

[10] Loubet N et al 2017 Stacked nanosheet gate-all-around transistor to enable scaling beyond FinFET Dig. Tech. Pap.-Symp. VLSI Technol. vol 5 pp T230-1

[11] Wirths $\mathrm{S}$ et al $2014 \mathrm{Ni}(\mathrm{SiGeSn})$ metal contact formation on low bandgap strained $(\mathrm{Si}) \mathrm{Ge}(\mathrm{Sn})$ semiconductors $E C S$ Trans. 64 107-12

[12] Schulte-Braucks C et al 2016 Low temperature deposition of high-k/metal gate stacks on high-Sn content (Si)GeSn-alloys ACS Appl. Mater. Interfaces 8 13133-9
[13] Wang L et al 2012 Metal stanogermanide contacts with enhanced thermal stability for high mobility germanium-tin field-effect transistor Int. Symp. VLSI Technol. Syst. Appl. Proc. vol 4 pp 4-5

[14] Schulte-Braucks C et al 2017 Schottky barrier tuning via dopant segregation in NiGeSn-GeSn contacts J. Appl. Phys. 121205705

[15] Gupta S et al 2013 Highly selective dry etching of germanium over germanium-Tin $\left(\mathrm{Ge}_{1-x} \mathrm{Sn}_{x}\right)$ : a novel route for $\mathrm{Ge}_{1-x}$ $\mathrm{Sn}_{x}$ nanostructure fabrication Nano Lett. 13 3783-90

[16] Shang C K et al 2016 Dry-wet digital etching of $\mathrm{Ge}_{1-x} \mathrm{Sn}_{x}$ Appl. Phys. Lett. 108183102

[17] Lei D et al The first GeSn FinFET on a novel GeSnOI substrate achieving lowest $\mathrm{S}$ of $79 \mathrm{mV} /$ decade and record high $\mathrm{Gm}$, int of $807 \mu \mathrm{S} / \mu \mathrm{m}$ for GeSn P-FETs 2017 Symp. on VLSI Technology (June 2017) pp T198-9

[18] Cardinaud C, Peignon M-C and Tessier P-Y 2000 Plasma etching: principles, mechanisms, application to micro- and nano-technologies Appl. Surf. Sci. 164 72-83

[19] Aubin J, Hartmann J M, Barnes J P, Pin J B and Bauer M 2017 Very low temperature epitaxy of heavily in situ phosphorous doped Ge layers and high Sn content GeSn layers ECS J. Solid State Sci. Technol. 6 P21-P26 